\title{
A Case Report of Successful Management with Long Term Survival of Basal Cell Carcinoma of the Internal Canthus of the Right Eye
}

\author{
Mohamed Réda Khmamouche ${ }^{1,2 *}$, Mehdi Khmamouche ${ }^{3}$, Mohamed Amine Essaoudi ${ }^{4}$, Tarik Mahfoud ${ }^{1}$, Rachid Tanz ${ }^{1}$ \\ and Mohamed Ichou ${ }^{I}$
}

${ }^{1}$ Department of Medical Oncology, Military Hospital Mohammed V, Rabat, Morocco

${ }^{2}$ Department of Medical Oncology, Hassan II University Hospital, Sidi Mohamed Ben Abdellah University, Fez, Morocco

${ }^{3}$ Department of Ophthalmology, Military Hospital Mohammed V, Rabat, Morocco

${ }^{4}$ Department of Pathological Anatomy, Military Hospital Mohammed V, Rabat, Morocco

\begin{tabular}{l} 
A R T I C L E I N F O \\
\hline Article history: \\
Received: 2 November, 2021 \\
Accepted: 18 November, 2021 \\
Published: 3 December, 2021 \\
\hline Keywords: \\
Basal cell carcinoma \\
surgery \\
radiotherapy \\
orbit \\
vismodegib \\
imiquimod \\
electrochemotherapy
\end{tabular}

\begin{abstract}
A B S T R A C T
Basal cell carcinoma (BCC) is the most frequently occurring malignant periocular tumor. The aim of treatment remains surgery with negative margins. We report a case of 65-year-old woman who was diagnosed with BCC of internal canthus of the right eye, in October 2011. The patient was treated by surgical resection in 2 steps with reconstruction by a frontal flap. The treatment resulted in complete remission without any recurrence after ten years of surgery.
\end{abstract}

(C) 2021 Mohamed Réda Khmamouche. Hosting by Science Repository.

\section{Introduction}

Basal cell carcinoma (BCC) is the most frequent skin cancer in the world and accounts for $90 \%$ of all tumors on the eyelid with a slight male preponderance $[1,2]$. The most common periorbital site for BCC is the lower eyelid, followed by the internal or medial canthus, upper eyelid, and external or lateral canthus [3]. The most important predisposing factor described in the literature is prolonged exposure to sunlight, which explains why the tumor occurs more frequently on the lower eyelid [4]. The aim of treatment is complete tumor resection with negative margins in order to prevent recurrence [5]. The incidence of orbital invasion is nearly $2-4 \%$, and risk factors include large lesion size, multiple recurrences, aggressive histological subtype, internal canthus location, and advanced patient age [5]. Although the occurrence of metastasis is rare, $\mathrm{BCC}$ of the eyelids has a high risk of recurrence. The prognosis of
BCC is good if it is diagnosed early, and the function and the appearance of the eyelid will be preserved [6]. Therefore, complete surgery promises better treatment outcomes, including functionality and aesthetic outcomes [6]. The best treatment option for BCC is surgery, including Mohs Micrographic Surgery (MMS) and wide surgical excision in order to reduce the risk of local recurrence and it remains the goal of treatment. Other several modalities can also be used in BCC, such as radiotherapy, cyberknife in stereotactic body radiation therapy (SBRT) or immunotherapy [7-9].

\section{Case Report}

A 65-year-old women with no medical or surgical past history presented with ulceration of internal canthus of the right eye with redness and eye tearing in October 2011. Physical examination by ophthalmologist found on the right eye: visual acuity of 5/10, conjunctival hyperaemia with

${ }^{*}$ Correspondence to: Dr. Mohamed Réda Khmamouche, Medical Oncologist, Department of Medical Oncology, Military Hospital Mohammed V, Rabat, Hassan II University Hospital, Sidi Mohamed Ben Abdellah University, Fez, Morocco; E-mail: redastos@hotmail.com 
purulent secretions, superficial punctate keratitis, a nuclear cataract and an ulcerous lesion infiltrating the internal canthus invading the median $1 / 4$ of the two eyelids (lachrymal ducts) (Figure 1). A biopsy for histological analysis was performed and confirmed the diagnosis of sclerodermiform type basal cell carcinoma of the internal canthus of the right eye (Figure 2). Initial therapy was surgical resection, and the patient was treated with 2 steps by ophthalmologist and plastic surgeon: In the first time: a large carcinological excision with $1.5 \mathrm{~cm}$ of safety margin and reconstruction of the loss of latero-nasal substance and internal canthus by a frontal flap (Figure 3). In the second step: retouch of the flap to reconstruct the palpebral fissure (Figure 4).

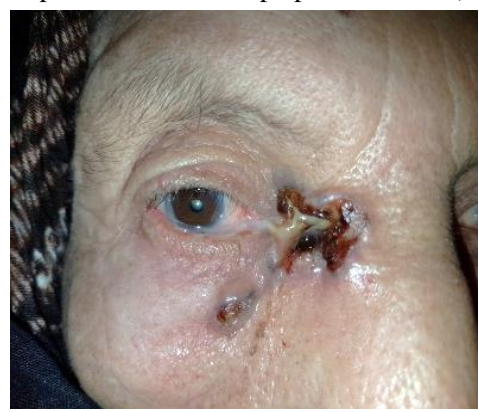

Figure 1: Appearance of the tumor of the internal canthus before surgery. Image shows ulcerous lesion infiltrating the internal canthus invading the median $1 / 4$ of the two eyelids (lachrymal ducts).

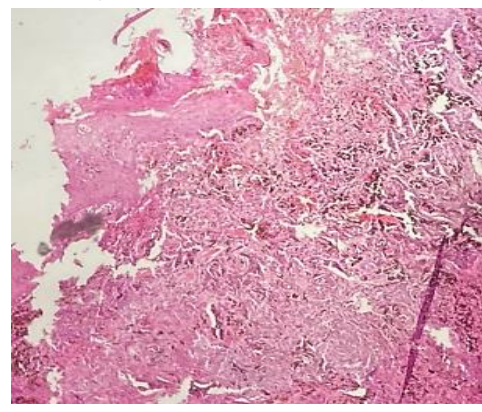

Figure 2: Basal cell carcinoma HE Gx10.

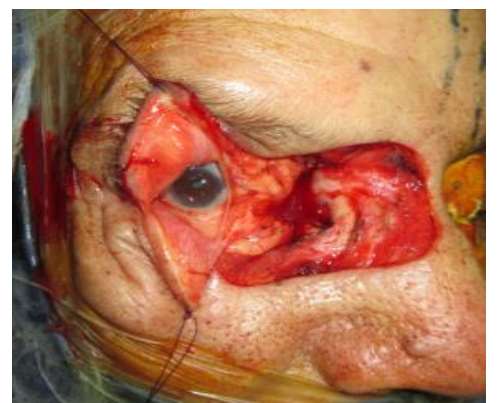

Figure 3: A large carcinological excision of the lesion and reconstruction of the loss of latero-nasal substance and internal canthus by a frontal flap.



Figure 4: Image showing retouch of the flap to reconstruct the palpebral fissure.
The locoregional and distant extension workup did not show any secondary localization. Adjuvant radiotherapy was discussed at the multidisciplinary staff, but the indication was not retained. The patient was put under surveillance every 3 months for one year then every 6 months. The patient had no recurrence of her disease with complete clinical remission after ten years of complete surgical excision.

\section{Discussion}

Basal cell carcinoma (BCC) is the most frequent skin cancer in the world and accounts for $90 \%$ of all tumors on the eyelid with a slight male preponderance $[1,2]$. The most common periorbital site for BCC is the lower eyelid, followed by the internal or medial canthus, upper eyelid, and external or lateral canthus [3]. Intense exposure to ultraviolet (UV) radiation is one of the most important known risk factors of BCC $[4,6]$ Other risk factors for the development of BCC reported in literature include family history of skin cancers, immunosuppression, previous treatment by radiotherapy and chronic exposure to toxic substances [6, 10]. As clinical signs are variable, the final diagnosis of tumors must always be histological, for which, pathological examination is required. A Biopsy is essential for all suspicious lesions [6]. The histological classification described by Wade and Ackerman recognized 9 types of BCC: solid, nodular, nodular-ulcerative, infiltrative, morpheaform, cystic, nodular-cystic, basosquamous, and plexiform (adenoid pattern) [11]. The nodular BCC was the most frequent histological type. Different modalities demonstrate efficacy in periocular BCC. We present a brief summary of these therapeutic modalities for BCC in (Table 1).

Table 1: Treatment modalities of periorbital BCC.

\begin{tabular}{|c|c|}
\hline Treatment modality & Indications \\
\hline $\begin{array}{l}\text { Mohs micrographic } \\
\text { surgery }\end{array}$ & $\begin{array}{l}\text { The best choice of removing } \mathrm{BCC} \text { on the } \\
\text { eyelid with wide surgical excision }\end{array}$ \\
\hline Exenteration & Bulbar or extensive orbital invasion \\
\hline Radiotherapy & $\begin{array}{l}\text { Combined with, when margins are not } \\
\text { clear or followed by, exenteration of high- } \\
\text { risk histological subtype } \\
\text { (morphoeic/infiltrative, micronodular or } \\
\text { basosquamous) with perineural invasion }\end{array}$ \\
\hline Vismodegib & $\begin{array}{l}\text { Adjuvant therapy of periocular and orbital } \\
\text { BCC for patients who cannot tolerate } \\
\text { surgery or radiotherapy, or with relapsed } \\
\text { locally advanced disease after surgery or } \\
\text { metastatic disease }\end{array}$ \\
\hline Imiquimod & $\begin{array}{l}\text { A topical immunotherapy for periocular } \\
\text { BCC, especially periocular nodular BCC }\end{array}$ \\
\hline
\end{tabular}

\section{Surgery}

Surgery remains the best option for the treatment of BCC, including both Mohs Micrographic Surgery (MMS) and wide surgical excision with negative resection margins control. Complete resection reduces the risk of local recurrence. A cure rate of about $95 \%$ is achieved after surgical treatment, depending on the localization, the size and histological type of the BCC. Following surgery, the relapse rate is less than 5\% per year [7-9]. The objective of surgery is to excise the tumor totally (margins of $3 \mathrm{~mm}$ outside the tumor) and reestablish the functionality and aesthetics 
of eyelids. The UK National Multidisciplinary Guidelines recommend that non-infiltrative BCC, $2 \mathrm{~cm}$, be excised with a margin of $4-5 \mathrm{~mm}$. Smaller margins $(2-3 \mathrm{~mm})$ may be considered in case of limited reconstructive options [12].

A randomized study published in the British Journal of Cancer in 1997 compared MMS to radiotherapy in 347 patients with BCC of $4 \mathrm{~cm}$ size in the face conclude that surgery cosmetic results were better than radiotherapy (MMS vs radiotherapy: $87 \%$ vs. 69\%) [13]. Several studies suggest that specific locations such as medial canthus and some histological differentiation such as morpheaform or sclerosing BCC may be associated with incomplete resection with higher recurrence rates [4]. In our patient, the location of the medial canthus is associated with no recurrence after 10 years of surgery. Most interesting, several investigators associate MMS with lower incomplete excision and recurrence rate $[8,14]$. However, MMS is not commonly recommended for deep orbital invasion because it is always difficult to obtain correct oriented specimens from the orbital soft tissues. Also, the risk of falsenegative results with standard frozen section techniques is important. Reconstruction of the exenteration of the orbit generally use splitthickness skin grafts, temporalis free flaps or muscle flaps [15, 16]. Exenteration is indicated in cases of bulbar or extensive orbital invasion. It may be combined with adjuvant radiotherapy for suspected resection margins or in high-risk aggressive tumors with perineural invasion [5]. When the lesion involves internal or medial canthus, margin-controlled excision are not necessary at initial treatment; however, when pathological analysis shows an infiltrative subtype, exenteration is strongly recommended [6].

\section{Radiotherapy}

Radiotherapy is used as an adjuvant therapy to excision with clear margins but may be followed by exenteration of high-risk aggressive BCC with perineural invasion or for inoperable tumors. It is also used for BCC patients who surgery is contraindicated. Radiotherapy has more local side effects, including ectropion, stenosis of lacrimal duct, dry eye, cataract formation, radiation retinopathy, neovascular glaucoma, and radiation optic neuropathy, and can even cause significant ocular morbidity or blindness. About $25 \%$ of patients undergo radiotherapy alone for invasive orbital BCC relapse [16, 17]. Swanson et al. reported in 2005 the outcomes for patients with BCC of the medial canthus after primary radiotherapy for gross disease or adjuvant radiotherapy following surgical resection. 33 patients were included. This study concluded that radiotherapy produces excellent results in almost all patients with BCC of the medial canthus exceptionally for the group of patients with recurrent tumors and voluminous disease at the time of radiotherapy [18].

Pontoriero et al. reported a 73-year-old man with recurrent nodular BCC in the inner canthus of the left eye involving the extrinsic muscles of the orbit and periorbital fat. He was treated successfully with cyberknife in stereotactic body radiation therapy (SBRT) modality alone. After the treatment, the patient enjoyed rapid tumor regression, with prolonged complete remission and preserved visual function after 6 months. According to this study, this therapeutic modality is feasible and could be proposed for elderly patients who refuse brachytherapy, or for patients unfit for surgery [3].

\section{Vismodegib}

Several genetic mutations have been identified in BCC. These mutations result in a hyperactivation of the Hedgehog $(\mathrm{Hh})$ signaling pathway. The Hh pathway is mainly involved in embryonic development. It is mostly quiescent in adults. It plays a role in the renewal of stem cells and in the maintenance of tissue homeostasis. For the last ten years, the pharmaceutical industry has been developing new drugs capable of inhibiting the $\mathrm{Hh}$ signaling pathway. Vismodegib is the first orally hedgehog pathway inhibitor, used as a medical or adjuvant therapy of periocular and orbital BCC to decrease tumor size [19]. Marketing Authorization of this drug was obtained in 2013. It is indicated for the treatment of adults with metastatic basal cell carcinoma, or with locally advanced basal cell carcinoma that has recurred following surgery or who are not candidates for surgery or radiation [20]. In case of metastasis, lymphatic nodes (40-83\%), lungs (35-53\%) and bones (20$28 \%)$ are mostly affected in BCC [21].

Vismodegib is available as a $150 \mathrm{mg}$ oral use capsule. It is dosed at 150 mg orally per day until disease progression or unacceptable toxicity [6]. The most common adverse effects of this drug include muscle spasms (72\%), fatigue (40\%), alopecia (64\%), dysgeusia (55\%), and weight loss $(45 \%)$. Other adverse effects associated with vismodegib include diarrhea, constipation, nausea, anorexia, ageusia, and arthralgias. Some patients may experience electrolyte disturbances, including hypokalemia or hyponatremia. In addition, the drug may induce the development of squamous cell cancer. That's why, all patients prescribed vismodegib require surveillance [22, 23].

\section{Imiquimod (IMQ)}

Surgical excision is considered a standard treatment for nodular basal cell carcinoma. However, patients who reject or are unsuited for surgery may benefit from topical immunotherapy imiquimod (IMQ) 5\% cream as an alternative treatment for periocular BCC [6]. The exact mechanism of action of imiquimod in superficial BCC is unknown [24]. It is a new topical immune modulator that stimulates innate and adaptive immunity and causes apoptosis in tumor cells. Numerous trials have reported the use of IMQ in a 5\% cream for nodular BCC. It is typically applied once per day, five times per week for 8-16 weeks depending on the patient situation. The symptoms of periocular BCC, including conjunctival irritation, conjunctivitis, lacrimation, keratitis, low visual acuity, ectropion and discomfort with blinking, usually disappear when treatment ends [6, 25]. A recent review published in 2020 included 39 publications, about using IMQ in the treatment of BCC of all localizations [26]. Regimens ranged from once daily 2 days a week to twice daily 7 days a week. The average treatment duration was 8.81 $( \pm 3.49)$ weeks. There was a $1.80 \%$ recurrence rate after an average follow-up period of $13.03( \pm 15.09)$ months. The author concludes that imiquimod showed clinical and histological clearance rates of over $70 \%$ for nodular BCC, with a recurrence rate of $1.80 \%$. Although clearance rates are lower than surgery, IMQ can be considered as a treatment option for patients who decline or are unfit for surgical intervention.

\section{Chemotherapy}

In $\mathrm{BCC}$, chemotherapy is not used for local stage; drugs such as cisplatin and 5-fluorouracil (5-FU) might be options if the disease spreads. These 
drugs are given intravenously, usually once every few weeks. In some cases, they might shrink tumors enough so that other treatments such as surgery or radiation therapy can be used. Basal cell carcinoma very rarely reaches an advanced stage, so, systemic chemotherapy is not typically used to treat these cancers. Advanced BCC is more likely to be treated with targeted therapy [27]. Electrochemotherapy (ECT) has recently been successfully added to the existing treatments for skin and superficial soft tissue metastases and irresectable primary cutaneous tumors in clinical practice [28]. This modality proved to be an efficient, safe and cost-effective treatment option. Various drugs have been tested: Bleomycin and cisplatin have been proved to be the most effective agents and consequently they are the most frequently used chemotherapeutic drugs during ECT [29, 30]. Although there are increasing evidences about the benefit of ECT in the head and neck region, only a few patients with $\mathrm{BCC}$ of the eyelid treated with ECT have been reported [31].

A recent study included 12 patients with periocular BCC. The administration of bleomycin was intratumoral in 3 patients and intravenous in 9 patients. The most common adverse local events were mild edema, hyperemia and mild pain. $75 \%$ of patients with recurrent tumors and $25 \%$ of cases with primary tumors were treated. Eight patients had tumors not only in the periocular area, but also in other extra orbital skin locations. Complete response was obtained in all 12 cases in the periocular localization [31]. In cases of elderly patients with various co-morbidities, this treatment represents a good therapeutic option with low systemic burden and fast recovery. ECT can be used in previously irradiated skin areas, where the excision of the recurrent tumor is difficult, and the success of other interventions is also limited. Patients with genetic susceptibility such as Gorlin-Goltz syndrome and xeroderma pigmentosum could also be efficacy treated with ECT. Furthermore, this modality could be used successfully in a vismodegibresistant case [31].

\section{Conclusion}

Adequate treatment of locally, advanced or recurrent periocular BCC is particularly difficult, as not only oncological, but also functional (vision) and cosmetic aspects should be considered with a multidisciplinary team when the most appropriate regimens are planned. It's very important to make an early diagnosis and to treat this malignant tumor quickly to preserve the visual prognosis.

\section{Conflicts of Interest}

None.

\section{Consent}

Consent to publish this case report was obtained from the patient.

\author{
Abbreviation \\ BCC: Basal Cell Carcinoma \\ MMS: Mohs Micrographic Surgery \\ SBRT: Stereotactic Body Radiation Therapy \\ Hh Pathway: Hedgehog Pathway \\ IMQ: Imiquimod
}

5-FU: 5-Fluoro-Uracil

ECT: Electrochemotherapy

\section{REFERENCES}

1. Margo CE, Waltz K (1993) Basal cell carcinoma of the eyelid and periocular skin. Surv Ophthalmol 38: 169-192. [Crossref]

2. Saleh GM, Desai P, Collin JRO, Ives A, Jones T et al. (2017) Incidence of eyelid basal cell carcinoma in England: 2000-2010. Br J Ophthalmol 101: 209-212. [Crossref]

3. Pontoriero A, Iatì G, Conti A, Minutoli F, Bottari A et al. (2014) Treatment of periocular basal cell carcinoma using an advanced stereotactic device. Anticancer Res 34: 873-875. [Crossref]

4. Simon GJB, Lukovetsky S, Lavinsky F, Rosen N, Rosner M (2012) Histological and clinical features of primary and recurrent periocular Basal cell carcinoma. ISRN Ophthalmol 2012: 354829. [Crossref]

5. Iuliano A, Strianese D, Uccello G, Diplomatico A, Tebaldi S et al. (2012) Risk factors for orbital exenteration in periocular Basal cell carcinoma. Am J Ophthalmol 153: 238-241. [Crossref]

6. Shi Y, Jia R, Fan X (2017) Ocular basal cell carcinoma: a brief literature review of clinical diagnosis and treatment. Onco Targets Ther 10: 2483-2489. [Crossref]

7. Zhang L, Huang X, Zhu X, Ge S, Gilson E et al. (2016) Differential senescence capacities in meibomian gland carcinoma and basal cell carcinoma. Int J Cancer 138: 1442-1452. [Crossref]

8. Malhotra R, Huilgol SC, Huynh NT, Selva D (2004) The Australian Mohs database, part I: periocular basal cell carcinoma experience over 7 years. Ophthalmology 111: 624-630. [Crossref]

9. Harvey DT, Taylor RS, Itani KM, Loewinger RJ (2013) Mohs micrographic surgery of the eyelid: an overview of anatomy, pathophysiology, and reconstruction options. Dermatol Surg 39: 673697. [Crossref]

10. Situm M, Buljan M, Bulat V, Mihic' LL, Bolanca $Z$ et al. (2008) The role of UV radiation in the development of basal cell carcinoma. Coll Antropol 32: 167-170. [Crossref]

11. Wade TR, Ackerman AB (1978) The many faces of basal-cell carcinoma. J Dermatol Surg Oncol 4: 23-28. [Crossref]

12. Newlands C, Currie R, Memon A, Whitaker S, Woolford T (2016) Non-melanoma skin cancer: United Kingdom National Multidisciplinary Guidelines. J Laryngol Otol 130: S125-S132. [Crossref]

13. Avril MF, Auperin A, Margulis A, Gerbaulet A, Duvillard P et al. (1997) Basal cell carcinoma of the face: surgery or radiotherapy? Results of a randomized study. Br J Cancer 76: 100-106. [Crossref]

14. Nemet AY, Deckel Y, Martin PA, Kourt G, Chilov M et al. (2006) Management of periocular basal and squamous cell carcinoma: a series of 485 cases. Am J Ophthalmol 142: 293-297. [Crossref]

15. Echchaoui A, Benyachou M, Houssa A, Kajout M, Oufkir AA et al. (2016) [Management of eyelid carcinomas: Retrospective bicentric study of 64 cases and review of the literature]. J Fr Ophtalmol 39: 187 194. [Crossref]

16. Sun MT, Wu A, Figueira E, Huilgol S, Selva D (2015) Management of periorbital basal cell carcinoma with orbital invasion. Future Oncol 11: 3003-3010. [Crossref]

17. Leibovitch I, McNab A, Sullivan T, Davis G, Selva D (2005) Orbital invasion by periocular basal cell carcinoma. Ophthalmology 112: 717723. [Crossref] 
18. Swanson EL, Morris CG, Kirwan J, Mendenhall WM, Amdur RJ Radiotherapy for Basal Cell Carcinomas of the Medial Canthus. Abstract 2559 Proceedings of the 50th Annual ASTRO Meeting.

19. Dirix L, Rutten A (2012) Vismodegib: a promising drug in the treatment of basal cell carcinomas. Future Oncol 8: 915-928. [Crossref]

20. Rudin CM (2012) Vismodegib. Clin Cancer Res 18: 3218-3222. [Crossref]

21. Ting PT, Kasper R, Arlette JP (2005) Metastatic basal cell carcinoma: report of two cases and literature review. J Cutan Med Surg 9: 10-15. [Crossref]

22. Koelblinger P, Lang R (2018) New developments in the treatment of basal cell carcinoma: update on current and emerging treatment options with a focus on vismodegib. Onco Targets Ther 11: 8327-8340. [Crossref]

23. Woltsche N, Pichler N, Wolf I, Di Meo N, Zalaudek I (2019) Managing adverse effects by dose reduction during routine treatment of locally advanced basal cell carcinoma with the hedgehog inhibitor vismodegib: a single centre experience. J Eur Acad Dermatol Venereol 33: e144e145. [Crossref]

24. Oldfield V, Keating GM, Perry CM (2005) Imiquimod: in superficial basal carcinoma. Am J Clin Dermatol 6: 195-200. [Crossref]
25. de Macedo EMS, Carneiro RC, de Lima PP, Silva BG, Matayoshi S (2015) Imiquimod cream efficacy in the treatment of periocular nodular basal cell carcinoma: a non-randomized trial. BMC Ophthalmol 15: 35. [Crossref]

26. Huang CM, Kirchhof MG (2020) Topical Imiquimod as a Treatment Option for Nodular Basal Cell Carcinoma: A Systematic Review. $J$ Cutan Med Surg 24: 495-503. [Crossref]

27. Martins RG Systemic treatment of advanced cutaneous squamous and basal cell carcinomas.

28. Miklavčič D, Mali B, Kos B, Heller R, Serša G (2014) Electrochemotherapy: from the drawing board into the medical practice. Biomed Eng Online 13: 29. [Crossref]

29. Mali B, Jarm T, Snoj M, Sersa G, Miklavcic D (2013) Antitumoral effectiveness of electrochemotherapy: a systematic review and metaanalysis. Eur J Surg Oncol 39: 4-16. [Crossref]

30. Kis EG, Baltás E, Ócsai H, Vass A, Németh IB et al. (2019) Electrochemotherapy in the treatment of locally advanced or recurrent eyelid-periocular basal cell carcinomas. Sci Rep 9: 4285. [Crossref]

31. Salwa SP, Bourke MG, Forde PF, O'Shaughnessy M, O'Sullivan ST et al. (2014) Electrochemotherapy for the treatment of ocular basal cell carcinoma; a novel adjunct in the disease management. J Plast Reconstr Anesthet Surg 67: 403-406. [Crossref] 